\title{
The dual role of ammonium acetate as reagent and catalyst in the synthesis of $2,4,5$-triaryl-1H- imidazoles
}

\author{
Reza Tayebee $^{a, *}$ | Ali Goharib \\ ${ }^{a}$ Department of Chemistry, School of Sciences, \\ Hakim Sabzevari University, Sabzevar, 96179- \\ 76487, Iran \\ ${ }^{b}$ Department of Biochemistry, School of \\ Medicine, Sabzevar University of Medical \\ Sciences, Sabzevar, Iran
}

The new findings concerning synthesis of some 2, 4, 5-triaryl$1 \mathrm{H}$-imidazoles is disclosed in the absence of any catalyst. Results indicated that by enhancing the amount of ammonium acetate, an obvious acceleration can be observed in the reaction progress. It is believed that ammonium acetate should be converted to ammonia and acetic acid during the reaction and the produced acid can catalyze the reaction progress. We believe that the observed efficiency for the previously reported catalytic systems has been mainly due to the presence of high molar ratio of ammonium acetate in the reaction medium and presence of auxiliary catalyst only improved the yield $\%$.

\section{KEYWORDS}

Tri-aryl-imidazoles; multi-component; green synthesis; catalytic evaluation; ammonium acetate.

\author{
*Corresponding Author: \\ Reza Tayebee \\ Email: rtayebee@hsu.ac.ir \\ Tel.: +98 (51) 44013212
}

\section{Introduction}

Over this century, the importance of imidazoles in biological systems has attracted a great deal of interest due to their biochemical properties. Compounds containing imidazole ring have many pharmaceutical properties and can play important roles in many natural biochemical processes [1-2]. For example, it is reported that substituted imidazoles can act as inhibitors of P38 MAP kinase [3], glucagon receotoranagonists [4], B-Raf kinase [5], antibacterial [6], plants growth regulators [7], antitumour [8], therapeutic agents [9], and also pesticides [10]. Moreover, the potency and wide application of the imidazole phrmacophores in biological systems can be attributed to its hydrogen bond donoracceptor capability as well as its high affinity to metals which are present in many protein active sites. Because of their wide range of pharmacological activity, industrial and synthetic applications, the synthesis of imidazoles has received considerable attention in recent years.

Multicomponent reactions (MCRs) have attracted great interest enjoying an outstanding position in modern green organic synthesis and medicinal chemistry because of the one-pot nature of these processes, bringing together three or more components and show high atom economy and high selectivity [11-12]. MCRs have great contribution in the convergent synthesis of complex and important organic medicinal molecules from simple and readily available starting materials, and have been emerged as powerful tools for drug discovery [13]. Various effective methods have been reported for synthesis of 2, 4, 5-triaryl-1Himidazoles [14-16]. However, these methods may suffer from one or more disadvantages, such as long reaction time, low yields, use of dangerous reagents or expensive instrumentation, and often difficult work-up.

Although there are several methods for the synthesis of 2, 4, 5-triaryl- $1 \mathrm{H}$-imidazoles 
from benzil/benzoin, aromatic aldehydes, and ammonium acetate using different catalysts such as ammonium chloride [17], poly(AMPSco-AA) [18], $\mathrm{NiFe}_{2} \mathrm{O}_{4}$ [19], Caro's acid-silica gel [20], and ionic liquids [21], development of new strategies for the preparation of 2, 4, 5-triaryl- $1 H$-imidazole derivatives is still a demand. Preparation of 2, 4, 5-triaryl- $1 \mathrm{H}$ imidazoles needs at least 2 moles of ammonium acetate against each mole of benzil (Scheme 1). However, most of reported catalytic procedures had used 4-8 mole of $\mathrm{NH}_{4} \mathrm{OAc}$ per each mole of diketone or benzil. Recently, we have found that this reaction is mainly catalyzed by $>8$ mol ratio of $\mathrm{NH}_{4} \mathrm{OAc}$ and led to $>70 \%$ of the corresponding imidazoles.

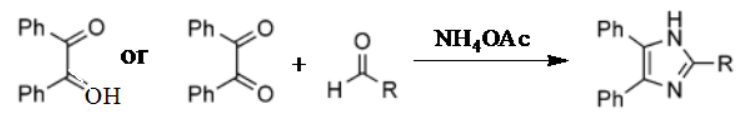

SCHEME 1 A general route for the preparation of 2, 4, 5-triaryl- $1 H$-imidazoles

\section{Experimental section}

\section{Materials and methods}

All starting materials were purchased commercially and were used as received. All products were characterized by comparison of their spectral and physical data with those reported in the literature. Silica gel 60 (70230 mesh) was used for column chromatography. Progress of the reactions was monitored by TLC. Infrared spectra were recorded ( $\mathrm{KBr}$ pellets) on a 8700 Shimadzu Fourier Transform spectrophotometer. ${ }^{1}$ HNMR spectra were recorded on a Bruker AVANCE 300-MHz instrument.

\section{Synthesis of 2, 4, 5-triaryl-1H-imidazoles}

A mixture of benzaldehyde (10 mmol, 0.106 g), benzil (10 mmol, $0.210 \mathrm{~g}$ ), and ammonium acetate was refluxed with stirring in ethanol for $40 \mathrm{~min}$ and progress of the reaction was subsequently monitored by TLC. Finally, the reaction mixture was cooled and poured into ice-water to get the solid precipitate. The obtained precipitate was collected by filtration, washed with water and dried to give the corresponding crude 2, 4, 5-triaryl$1 \mathrm{H}$-imidazoles. The crude product can be purified by a simple washing with hot petroleum benzene to afford nearly pure product. Further purity was achieved by recrystallization from ethanol-water mixture or by column chromatography. All products were identified by means of IR and ${ }^{1} \mathrm{HNMR}$ spectroscopy and/or comparison of their melting points with those reported in the literature.

Spectral data of some prepared 2, 4, 5-triaryl1 H-imidazoles

2, 4, 5-Tripheyl-1H-imidazole. IR (KBr): 3452 $(\mathrm{N}-\mathrm{H}), 3050(\mathrm{C}-\mathrm{H}), 1602(\mathrm{C}=\mathrm{C}), 1583(\mathrm{C}=\mathrm{N})$ $\mathrm{cm}^{-1} .{ }^{1} \mathrm{HNMR}$ (DMSO): $\delta=7.53-7.64(\mathrm{~m}, 6 \mathrm{H})$, 7.67-7.71 (m, 3H), 7.85- 7.92 (m, 6H), 8.9 (bs, $1 \mathrm{H})$.

2, 4, 5-Tri(4-methylphenyl)- $1 \mathrm{H}$-imidazole. IR (KBr): $3450(\mathrm{~N}-\mathrm{H}), 1602(\mathrm{C}=\mathrm{C}), 1585$ $(\mathrm{C}=\mathrm{N}) \mathrm{cm}^{-1} .{ }^{1} \mathrm{HNMR}\left(\mathrm{CDCl}_{3}\right): \delta=2.30\left(\mathrm{~s}, \mathrm{CH}_{3}\right)$, 7.11-7.62 (m, 10H, Ph), $7.71(\mathrm{~d}, 2 \mathrm{H}, \mathrm{J}=10 \mathrm{~Hz}$, Ar), $7.33(\mathrm{~d}, 2 \mathrm{H}, \mathrm{J}=10 \mathrm{~Hz}, \mathrm{Ar})$.

2,4,5-Tri(4-methoxyphenyl)-1H-imidazole. IR (KBr): $3452(\mathrm{~N}-\mathrm{H}), 1610(\mathrm{C}=\mathrm{C}), 1576$ $(\mathrm{C}=\mathrm{N}), 1385(\mathrm{C}-\mathrm{O}) \mathrm{cm}^{-1} \cdot{ }^{1} \mathrm{HNMR}\left(\mathrm{CDCl}_{3}\right): \delta=$ $3.91\left(\mathrm{~s}, \mathrm{OCH}_{3}\right), 7.08(\mathrm{~d}, 2 \mathrm{H}, \mathrm{J}=8.8 \mathrm{~Hz}, \mathrm{Ar})$, 7.31-7.82 (m, 10H, Ph), 7.93 (d, 2H, J= $8.8 \mathrm{~Hz}$, Ar).

\section{Results and discussion}

In connection with our ongoing work on the synthesis of various heterocyclic compounds [22-29], we wish to report a facile procedure for preparation of imidazole derivatives without addition of any specific catalyst. As mentioned above, several methods are introduced for the synthesis of trisubstitutedimidazoles and their derivatives. In addition, the synthesis of these heterocycles has been usually performed in 
polar organic solvents such as ethanol, methanol, acetic acid, DMF and DMSO leading to complex isolation and recovery procedures. These processes also generate waste containing catalyst and solvent, which have to be recovered. The toxicity and volatile nature of many organic solvents, particularly chlorinated hydrocarbons that are widely used in huge amounts for organic reactions have allocated a serious threat to the environment. Thus, design of solvent-free catalytic reaction has received tremendous attention in recent green synthetic approaches.
In continuation of our research program on the use of simple inorganic non-toxic catalysts, we tested the efficacy of $\mathrm{KH}_{2} \mathrm{PO}_{4}$ as catalyst in ethanol under reflux condition (Table 1). Furthermore, preparation of the title compound has been reported with different amounts of ammonium acetate. For example, in the synthesis of this compound with $\mathrm{ZrOCl}_{2} .8 \mathrm{H}_{2} \mathrm{O}$ and sodium bisulfite, the mol ratios of benzealdehyde, benzil, and ammonium acetate were 2.4: 2: 8 and with phosphomolybdic acid the ratio of 2.4: 2: 6 had been selected [33]. Table 1 shows some catalytic systems using different amounts of $\mathrm{NH}_{4} \mathrm{OAc}$.

TABLE 1 Synthesis of 2, 4, 5-tripheyl-1H-imidazole with different catalysts

\begin{tabular}{cccccc}
\hline Catalyst & Benzil (mmol) & $\mathbf{N H}_{\mathbf{4}} \mathbf{O A c}(\mathbf{m m o l})$ & Time (min) & Yield (\%) & Ref. \\
\hline $\mathrm{KH}_{2} \mathrm{PO}_{4}$ & 10 & 20 & 40 & 93 & 30 \\
$\mathrm{ZrOCl}_{2} .8 \mathrm{H}_{2} \mathrm{O}$ & 10 & 40 & 30 & 97 & 31 \\
sodium bisulfite & 10 & 40 & 30 & 98 & 32 \\
phosphomolybdic & 10 & 30 & 45 & 97 & 33 \\
acid & & & & & \\
Boric acid $\left(\mathrm{H}_{3} \mathrm{BO}_{3}\right)$ & 1 & 3 & 30 & 98 & 34 \\
\hline
\end{tabular}

Efficiency of this reaction is mainly affected by the amount of ammonium acetate as catalyst. Thus, we performed this reaction with different mmols of ammonium acetate without using any additive to study the role of this initial substrate as catalyst. The results are presented in Table 2 .

TABLE 2 Synthesis of 2, 4, 5-tripheyl-1Himidazole with different amounts of ammonium acetate without any catalyst

\begin{tabular}{ccc}
$\begin{array}{c}\text { Mol ratio of } \\
\text { benzil: } \mathbf{N H}_{\mathbf{4}} \mathbf{O A c}\end{array}$ & $\begin{array}{c}\mathbf{N H}_{4} \mathbf{O A c} \\
\text { (mmol) }\end{array}$ & $\begin{array}{c}\text { Yield } \\
\text { (\%) }\end{array}$ \\
\hline $1: 2$ & 20 & 26 \\
$1: 3$ & 30 & 45 \\
$1: 4$ & 40 & 58 \\
$1: 5$ & 50 & 77 \\
\hline
\end{tabular}

The reactions were performed with benzaldehyde $(10$ mmol), benzil $(10 \mathrm{mmol})$ and different amounts of ammonium acetate in ethanol under reflux for $40 \mathrm{~min}$.

Results in Table 2 confirm that an obvious acceleration was observed in the reaction progress by increasing the amount of ammonium acetate. It has been found that ammonium acetate should be converted to ammonia and acetic acid during the reaction. Therefore, it seems that the produced acid can catalyze the reaction. Thus, the reaction with 1: 4 mol ratio of benzil: ammonium acetate led to $\sim 60 \%$ yield. This finding shows that the observed efficiency for the previously reported catalytic systems has been mainly due to the presence of a high molar ratio of ammonium acetate and presence of catalyst only improved the yield\%. We repeated the synthesis of 2,4,5-tripheyl- $1 \mathrm{H}$-imidazole according to Joshi et al. [35]. A mixture of benzaldehyde (10 $\mathrm{mmol})$, benzil $(10 \mathrm{mmol})$, ammonium acetate $(20 \mathrm{mmol})$, and potassium dihydrogen phosphate (5 mol \%) was refluxed with stirring in ethanol for 40 min. Despite the reported yield, 93\%, we obtained $32 \%$ under the same reaction conditions.

Eventually, to examine the efficiency and applicability of this protocol, the reaction was extended to other substituted aromatic 
aldehydes with the new condition in the absence of catalyst and some 2,4,5-triaryl- $1 \mathrm{H}$ imidazoles are prepared, as shown in Table 3. We examined some para-substituted aromatic aldehydes to establish the catalytic

TABLE 3 Synthesis of some representative 2, 4,5 -triaryl- $1 \mathrm{H}$-imidazoles in the presence of ammonium acetate importance of this catalytic system. We found that aldehydes bearing either electronwithdrawing or electron-donating groups performed equally well in the reaction.<smiles>O=C(C(=O)c1ccccc1)c1ccccc1</smiles><smiles>[R]C=CC(=O)ON</smiles><smiles>[R]c1nc(-c2ccccc2)c(-c2ccccc2)[nH]1</smiles>

\section{Aromatic aldehyde}<smiles>O=Cc1ccccc1</smiles><smiles>c1ccc(-c2nc(-c3ccccc3)c(-c3ccccc3)[nH]2)cc1</smiles><smiles>O=Cc1ccc(F)cc1</smiles><smiles>Fc1ccc(-c2nc(-c3ccccc3)c(-c3ccccc3)[nH]2)cc1</smiles><smiles>N#Cc1ccc(C=O)cc1</smiles><smiles>N#Cc1ccc(-c2nc(-c3ccccc3)c(-c3ccccc3)[nH]2)cc1</smiles><smiles>COc1ccc(C=O)cc1</smiles><smiles>COc1ccc(-c2nc(-c3ccccc3)c(-c3ccccc3)[nH]2)cc1</smiles><smiles>Cc1ccc(C=O)cc1</smiles><smiles>Cc1ccc(-c2nc(-c3ccccc3)c(-c3ccccc3)[nH]2)cc1</smiles> 


\section{Conclusion}

In summary, this paper describes a convenient and efficient method for the synthesis of biologically active trisubstitutedimidazoles through the threecomponent coupling of benzil, aromatic aldehydes, and ammonium acetate, acting as both reagent and catalyst. Reaction profile is very clean and no side products are formed. All the synthesized imidazoles have been characterized based on the spectral studies. We believe that this procedure is convenient and economic, and uses an eco-friendly mediator for the synthesis of trisubstitutedimidazolese. This report also illustrated the new findings on the synthesis of some 2,4,5-triaryl-1H-imidazoles in the absence of any additive as catalyst.

\section{Acknowledgements}

Partial financial support from the Research Council of Hakim Sabzevari University is greatly appreciated.

\section{Orcid:}

Reza Tayebee: https://www.orcid.org/00000003-1211-1472

\section{References}

[1] J.G. Lambardino, E.H. Wiseman, J. Med. Chem., 1974, 17, 1182-1188.

[2] A. Chawla, A. Sharma, A.K. Sharma, Der Pharm. Chem., 2012, 4, 116-140.

[3] J.C. Lee, J.T. Laydon, P.C. McDonnell, T.F. Gallagher, S. Kumar, D. Green, D. McNulty, M.J. Blumenthal, J.R. Keys, S.W.R. Vatter, J.E. Strickler, M.M. McLaughlin, I.R. Siemens, S.M. Fisher, G.P. Livi, J.R. White, J.L. Adams, P.R. Young, Nature, 1994, 372, 739-746.

[4] L.L. Chang, K.L. Sidler, M.A. Cascieri, S. Laszlo,G. Koch, B. Li, M. Maccoss, N. Mantlo,S. Okeefe, M. Pang, A. Rolando, W.K. Hangmann, Bioorg. Med. Chem. Lett., 2001, 11, 25492553.

[5] A.K. Takle, M.J.B. Brown, S. Davies, D.K. Dean, G. Francis, A. Gaiba, A.W. Hird, F.D.
King, P.J. Lovell, A. Naylor, A.D. Reith, J.G. Steadman, D.M. Wilson, Bioorg. Med. Chem. Lett., 2006, 16, 378-381.

[6] M. Antolini, A. Bozzoli, C. Ghiron, G. Kennedy, T. Rossi, A. Ursini, Bioorg. Med. Chem. Lett., 1999, 9, 1023-1028.

[7] R. Schmierer, H. Mildenberger, H. Buerstell, German Patent, 1987, 3, 61464; Chem. Abstr., 1988, 108, 37838.

[8] M. Antolini, A. Bozzoli, C. Ghiron, G. Kennedy, T. Rossi, A. Ursini, Bioorg. Med. Chem. Lett., 1999, 9, 1023-1028.

[9] J. Heeres, L.J.J. Backx, J.H. Mostmans, J. Van Custem, J. Med. Chem., 1979, 22, 10031005.

[10] T. Maier, R. Schmierer, K. Bauer, H. Bieringer, H. Buerstell, B. Sachse, U.S. Patent 1989, 4820335; Chem. Abstr., 1989, 111, $19494 \mathrm{w}$.

[11] A.R. Moosavi-Zare,, H. Goudarziafshar, Z. Jalilian, Prog. Chem. Biochem. Res., 2019,2, 59-63.

[12] M. Aghazadeh, Prog. Chem. Biochem. Res., 2019, 2, 34-39.

[13] M. Asif, I. Mohd, Prog. Chem. Biochem. Res., 2019, 2, 192-210.

[14] B. Maleki, S. Sedigh Ashrafi, J. Mexican Chem. Soc., 2014, 58, 76-81.

[15] B. Maleki, H.K. Shirvan, F. Taimazi, E. Akbarzadeh, Inter. J. Org. Chem., 2012, 2, 9399.

[16] M.M. Heravi, N. Karimi, S. Pooremami, Adv. J. Chem. A, 2019, 2, 73-78.

[17] B. Maleki, H. Keshvari, A. Mohammadi, Orient. J. Chem. A, 2012, 28, 1207-1212.

[18] A. Mohammadi, H. Keshvari, R. Sandaroos, B. Maleki, H. Rouhi, H. Moradi, Z. Sepehr, S. Damavandi, Appl. Catal. A: Gen., 2012, 429, 73-78.

[19] B. Maleki, H. Eshghi, A. Khojastehnezhad, R. Tayebee, S.S. Ashrafi, G.E. Kahoo, F. Moeinpour, RSC Advances, 2015, 5, 6485064857.

[20] M.M. Heravi, H. Hamidi, N. Karimi, A. Amouchi, Adv. J. Chem. A, 2018, 1, 1-6.

[21] B. Maleki, G.E. Kahoo, R. Tayebee, Org. Prep. Proced. Int., 2015, 47, 461-472. 
[22] H. Ramshini, R. Tayebee, A. Bigi, F. Bemporad, C. Cecchi, F. Chiti, Int. J. Mol. Sci., 2019, 20, 5558-5576.

[23] R. Tayebee, M. FattahiAbdizadeh, N. Erfaninia, A. Amiri, M. Baghayeri, R.M. Kakhki, B. Maleki, E. Esmaili, Appl. Organomet. Chem., 2019, 33, e4959.

[24] R. Tayebee, A.F. Lee, L. Frattini, S. Rostami, Catalysts, 2019, 9, 409-416.

[25] N. Erfaninia, R. Tayebee, E.L. Foletto, M.M. Amini, M. Dusek, F.M. Zonoz, Appl. Organomet. Chem., 2018, 32, e4047.

[26] N. Erfaninia, R. Tayebee, M. Dusek, M.M. Amini, Appl. Organomet. Chem., 2018, 32, e4307.

[27] R. Tayebee, A. Pejhan, H. Ramshini, B. Maleki, N. Erfaninia, Z. Tabatabaie, E. Esmaeili, Appl. Organomet. Chem., 2018, 32, e3924.

[28] F. Javadi, R. Tayebee, B. Bahramian, Appl. Organomet. Chem., 2017, 31, e3779.

[29] F. Javadi, R. Tayebee, Iran. J. Catal., 2017, 7, 283-292.

[30] B. Mirjalili, A. Bamoniri, N. Mohaghegh, Curr. Chem. Lett., 2013, 2, 35-42.
[31] J.N. Sangshetti, N.D. Kokare, S.A. Kotharkar, D.B. Shinde, Chin. Chem. Lett., 2008, 19, 762-766.

[32] J.N. Sangshetti, N.D. Kokare, S.A. Kotharkar, D.B. Shinde, Monat. für Chem.Chem. Mon, 2008, 139, 125-127.

[33] S.D. Jadhav, N.D. Kokare, S.D. Jadhav, J. Heterocycl. Chem., 2008, 45, 1461-1464.

[34] K.F. Shelke, S. Sapkal, S. Sonal, B.R. Madje, B.B. Shingate, M.S. Shingare, Bull. Kor. Chem. Soc., 2009, 30, 1057-1060.

[35] R.S. Joshi, P.G. Mandhan, M.U. Shaikh, R.P. Kale, C.H. Gill, Chin. Chem. Lett., 2010, 21, 429-432.

How to cite this article: Reza Tayebee*, Ali Gohari. The dual role of ammonium acetate as reagent and catalyst in the synthesis of 2,4,5-triaryl-1H-imidazoles. Eurasian Chemical Communications, 2020, 2(5), 581586.

Link: http://www.echemcom.com/article_101526 .html 